\title{
Death Anxiety among Asymptomatic Acute HIV Condition, Clinically Symptomatic Condition and Aids Indicator Condition Groups
}

\author{
Krishnamurthy V. S. ${ }^{1 *}$, Dr. Sampathkumar ${ }^{2}$
}

\section{ABSTRACT}

There is much interest in, whether death anxiety may explain the wide variability in the disease course of patients infected with Human Immunodeficiency Virus (HIV). This paper examines whether death anxiety varies across Asymptomatic Acute HIV condition, Clinically Symptomatic Condition and AIDS Indicator Condition. A cross sectional research design is employed and participants were grouped as having asymptomatic, clinically symptomatic and AIDS according to case definitions established by the Centers for Disease Control and Prevention. The data is obtained from 480 participants on the level of death anxiety and it is analysed with reference of their disease progression from HIV to AIDS. A one way ANOVA statistics indicated that Asymptomatic acute HIV condition, Clinically symptomatic HIV condition and AIDS indicator groups were significantly differ in the level of death anxiety. A Tukey's HSD post-hoc test indicated that clinically symptomatic acute HIV condition group had exhibited higher level of death anxiety than asymptomatic acute HIV condition group and lower level of death anxiety compared to AIDS indicator group. By knowing the varied level of death anxiety across disease progression the tailor made interventions can be planned.

Keywords: Human Immune Virus, Acquired Immunodeficiency Syndrome, Disease progression, Death-anxiety.

The Joint United Nations Programme on HIV/AIDS (UNAIDS) reported on 2015 World AIDS day that an estimated 369 lakh people are living with Human Immune deficiency Virus (HIV) infection worldwide (end 2014). There were 20 lakh people became newly infected with HIV (end 2014) and 12 lakh people died from AIDS-related causes worldwide. India is in third place where more number of people living with HIV in the world — 21 lakh at the end of 2013 — and accounts for about 4 out of 10 people living with HIV and India accounts for $51 \%$ of all AIDS-

\footnotetext{
${ }^{1}$ Ph. D. Research Scholar, Department of Studies in Psychology, University of Mysore, Mysuru

${ }^{2}$ Assistant Professor, Department of Studies in Psychology, University of Mysore, Mysuru

*Responding Author

(C) 2016 Krishnamurthy V, Sampathkumar; licensee IJIP. This is an Open Access Research distributed under the terms of the Creative Commons Attribution License (http://creativecommons.org/licenses/by/2.0), which permits unrestricted use, distribution, and reproduction in any Medium, provided the original work is properly cited.
} 
related deaths in the region. In India, though the numbers of new HIV infections declined by $19 \%$, still accounted for $38 \%$ of all new HIV infections in the county, this shows the severity of HIV disease still exist in our country.

Over the past 30 years medical and mental health professionals have progressively found themselves working with individuals and families affected by AIDS disease. As reported by Thomason, Bachanas and Campos (1997) cognitive behavioural therapists have the prospect to help persons with HIV+ to learn coping skills, admit physical limitations and keep up supportive relationships to get better quality of life. With the help of medical treatments and psychological assistance, a large percentage of these individuals have been able to lead otherwise healthy lives for many years. In improving the mental health and quality of life of HIV infected people, it's important to know the nature of progression of disease from HIV to AIDS.

\section{Stages and Physical Manifestations of HIV/AIDS}

HIV is a virus that infects white blood cells, mainly CD4 cells which are important parts of the immune system. The virus gradually destroys CD4 cells, reduces the performance of immune system functioning, disabling the body from resistance off infections and disease. The progression of disease from HIV to AIDS can be understood in three stages.

\section{Asymptomatic Period:}

In this stage, people who are infected with HIV experience no symptoms of the disease but remain capable of transmitting it to others. Procedural HIV testing for the presence of antibodies to HIV is the only way for the person to know if they are infected. The asymptomatic period lasts more or less from five to eight years. During this period the virus slowly infects and destroys CD4 cells. After a number of years, the collective loss of CD4 cells disables the body from fighting off infections and diseases. The average CD4 cell count in healthy person is around 1,000. Symptoms normally do not develop until a person's CD4 count is less than 300. Severe problems develop when the CD4 count goes below 100. Blood counts are routinely performed to monitor the progression of the disease.

\section{Early Symptomatic HIV Infection:}

First symptoms of immune system impairment become evident during the early symptomatic stage of infection. This period is also referred to as AIDS-related complex (ARC). The symptoms and conditions that develop during this period look like but are not as severe as symptoms that define the diagnosis of AIDS.

\section{Late Symptomatic HIV infection (AIDS):}

Occurs approximately eight years after the time of infection. AIDS defining conditions are opportunistic infections or tumours and a CD4 cell count below 200. During this period neuropsychological complications frequently develop. AIDS Dementia Complex (ADC) is the most 


\section{Death Anxiety among Asymptomatic Acute HIV Condition, Clinically Symptomatic Condition and Aids Indicator Condition Groups}

common neurological complication of AIDS and is defined as universal cognitive dysfunction due to brain infection caused by HIV. Cognitive impairment is usually characterized by mental slowing and problems in memory and attention.

A review of the literature demonstrates that frequent contributions in the severity of emotional disturbances in persons at different stages of AIDS illness. Ammassari et al. (2004) reported that anxiety and depression are the most common psychological symptoms reported by persons with HIV.Baer, Dwyer and Lewitter-Koehler (1988) shown that persons with HIV as a whole suffers from a high levelof subjective distress such as anxiety, fear, depression, desperation, suicidal ideation and guilt. Hintze, Templer, Cappelletty and Frederick (1993)reported that higher death anxiety and death depression were most highly correlated with rate of anxiety, trait anxiety, and depression. From the above studies it is understood that Death anxiety, suicidal ideation and guilt are common among HIV infected people. Hedge and Sherr (1995)says that many studies examining psychological disturbances in the said population have failed to utilize appropriate controls, classify symptomatic patients by severity of illness or provide asymptomatic comparison groups. This shows that there are considerable problems in examining the Psychological disturbances of HIV infected people.

The careful review of literatures indicates that one of the most commonly cited psychological sequelae of HIV/AIDS is anxiety regarding death due to the illness (i.e., death anxiety; DA) and its related psychological experiences. Miller, Lee and Henderson (2012) conducted a systematic review of the empirical literature and meta-analysis to answer certain questions concerning correlates of Death anxiety in persons with HIV/AIDS and important factors that may help explain variability in effect size estimates, The meta-analysis included 18 studies $(\mathrm{N}=1,757)$ examining Death anxiety in adults with HIV/AIDS, findings report a small-to-medium effect of HIV/AIDS diagnostic status on DA, which was moderated by duration since diagnosis and by relation to the advent of highly active antiretroviral therapy. Their results have also shown a small effect of illness-related symptoms on DA, which was moderated by participant's age, Social support and intrinsic religiosity were modest protective factors but results indicated that extrinsic religiosity may exacerbate or be exacerbated by DA. Over all, the results of their study indicated that a medium-to-large relation between psychological symptoms and DA.

There is much interest in, whether death anxiety may explain the wide variability in the disease course of patients infected with HIV. Perry, Jacobsberg, Fishman, Frankes, Bobo and Jacobsberg (1990) reported that both sero-positive and sero-negative subjectsexhibited high levels of psychological disturbances prior to notification of HIV status. After they know the results, the sero-negative population experienced a reduction of symptomatology but the sero-positive group remained at high elevations of emotional distress when measured 10 weeks after notification. In contrast to these findings, Jadresic, Ricco, Hawkins, Wilson, and Thompson (1994) reported that subjects testing positive initially reported increased psychopathology but 


\section{Death Anxiety among Asymptomatic Acute HIV Condition, Clinically Symptomatic Condition and Aids Indicator Condition Groups}

experienced a significant reduction of symptoms after six months. Franks, Templer, Cappelletty, \& Kauffman (1987) studied males afflicted with AIDS, and found greater death anxiety among persons with AIDS when compared to HIV negative controls. ARC and asymptomatic patients were not represented in this study. Research on death anxiety in the HIV population suffers from severe methodological flaws.

Furthermore knowledge is required to know how factors associated with survival among people living with HIV/AIDS which can provide useful Information on emerging issues to public health agencies for use in developing more effective prevention and treatment services, as well as evaluating public health interventions aimed at reducing morbidity and mortality among people with HIV/AIDS.

Limited studies have been conducted on death anxiety among people living with HIV/AIDS and none of the studies have been carried out across by considering all the three stages, namely Asymptomatic acute condition, Clinical symptomatic condition and AIDS indicator condition. There may be significant differences among people in their Psychological conditions across three stages of HIV/AIDS. Consequently the level of death anxiety also may vary accordingly among these three groups. By knowing that attempts can be made to reduce the level of death anxiety and interns improve their mental health. Hence the present study aimed at studying the level of death anxiety among asymptomatic acute HIV group, clinically symptomatic condition group and AIDS indicator Condition group.

\section{Problem}

- To study whether the death anxiety increases across disease progression from HIV to AIDS.

\section{Hypotheses}

- Clinically symptomatic acute HIV Condition group exhibits higher level of death anxiety compared to asymptomatic acute HIV condition group.

- Clinically symptomatic acute HIV condition group exhibits higher level of death anxiety compared to AIDS indicator condition group.

\section{METHOD}

The study employed a cross sectional research design in knowing the level of death anxiety across HIV/AIIDS disease progression. Death anxiety operationalized by the participants' responses to death anxiety scale and HIV phase i e Asymptomatic, Symptomatic and AIDS indicator groups as classified in Center for Disease Control and Prevention (CDC). 


\section{Participants}

The study consisted the total participants 480 People Living with HIV/AIDS (PLWHA). The purposive convenient sampling technique was used to select participants representing the three stages of HIV/AIDS disease progression namely- asymptomatic acute HIV group ( $N=160)$, clinically asymptomatic condition group $(N=160)$ and AIDS indicator Condition group $(N=160)$. The participants were drawn from community care centers like SNEHADHAN, SUPPORT, ACCEPT, KNP+, which are situated in and surround Bangaluru city and also PLWHA who comes for ART treatment for District ART centers and link ART centers in Karnataka.

\section{Inclusion criteria}

- People who have been medically diagnosed as HIV+ve.

- People who are able to respond (those who are not in chronicle condition) to the questionnaires.

- Both men and women in the age group of 20-45 years.

\section{Classification of groups}

Persons were classified as having HIV/AIDS according to case definitions established by the Centers for Disease Control and Prevention (Guidelines for national human immunodeficiency virus case surveillance including monitoring for human immunodeficiency virus infection and acquired immunodeficiency syndrome, 1999) HIV-infected persons with a documented Centers for Disease Control and Prevention AIDS-defining event [i.e., diagnosis of an opportunistic illness (OI) or CD4 count $<200$ cells/ $\mu \mathrm{L}$ ] were categorized as having been diagnosed with AIDS in the calendar event the earliest known AIDS defining event and CD 4 count $<500 / \mu \mathrm{L}$ were categorized as having been diagnosed with symptomatic acute HIV condition and CD4 count $>500$ cells $/ \mu \mathrm{L}$ were categorized as having been diagnosed with asymptomatic acute HIV condition.

\section{Measures}

1. Information Schedule: This schedule was developed to elicit detailed information regarding age, gender, educational level, occupational status, and three stages of HIV (obtained from medical officials/Competent ART counselors), duration of living with HIV and other demographic details.

2. Death Anxiety Scale (DAS): This scale was developed by Dr. (Mrs.) Vijayalaxmi Chouhan and Dr.(Mrs.) Gayatri Tiwari (1971) and it has 20 items. The DAS items reflect a wide range of life experiences such as fear of sickness, death, painful death, the future, sight of dead body, anxiety at thought of death, life after death, etc.

DAS has been tested for reliability by the authors using split-half reliability for full length, the reliability coefficient was 0.93 ,besides face validity as all items of the scale are concerned with the variable under focus, the scale has high content validity. It is evident from the assessment and rating of the judges/experts that items of the scale are directly related to the concept of death anxiety. In order to determine validity from the coefficient of reliability (Garrett), the reliability 


\section{Death Anxiety among Asymptomatic Acute HIV Condition, Clinically Symptomatic Condition and Aids Indicator Condition Groups}

index was calculated. The later has indicated high validity on account of being 0.74.An individual with a high score i.e. above (M+1 SD) may be considered to have very high level of death anxiety, symptomatic of such high state. He/she likely to have a disruptive and interfering influence and may be in need of counselling or psychotherapy. The low score i.e. below (M-1 SD) would represent especially "normal" individuals with moderately good drive to stimulate performance without any interference of the kind of anxiety under focus.

\section{Procedure}

After finalizing the information schedule and assessment techniques the subjects who were fulfilled the criteria were met personally. The purpose of assessment was explained to them on obtaining their consent then the assessment sessions are planned. In Order to facilitate the smooth conduct of interview, first the patients who are visiting the ART centers were taken for the study. Depending on the availability of leisure time and health condition of the subjects the interviews were held. The assessment was conducted in absolute privacy. To maximize frankness the subjects were assured of confidentiality and anonymity of responses and information revealed during the sessions.

The assessment was done on an individual, one to one basis with the researcher administering all the questionnaires personally. The information schedule and questionnaire was individually administered and subject's responses were noted down.

Items were repeated in case of difficulty in comprehending them. The same procedure is followed for both literate and illiterate subjects each session lasted for approximately 10 to 20 minutes and sessions were further continued till the full relevant data is gathered.

\section{ANALYSIS OF RESULTS}

Keeping in view the objectives of the study, in order to find out the significant mean differences among three groups belongs to asymptomatic acute HIV condition group, clinically symptomatic Condition group and AIDS indicator group one way ANOVA is calculated and in continuation of the statistical analysis to find out the significant mean difference between paired groups, Tukey's post hoc analysis was calculated and the obtained results have been shown. 
Death Anxiety among Asymptomatic Acute HIV Condition, Clinically Symptomatic Condition and Aids Indicator Condition Groups

Table 1, Shows the mean, standard deviation and ANOVA statistic son death anxiety among three groups belong to Symptomatic acute HIV group, clinically symptomatic HIV group and AIDS indicator group.

\begin{tabular}{|c|c|c|c|c|c|}
\hline \multirow{2}{*}{ Variable } & \multicolumn{3}{|c|}{ Death Anxiety } & \multirow[b]{2}{*}{$\mathrm{F}$} & \multirow[b]{2}{*}{$\mathrm{P}$} \\
\hline & $N$ & ${ }_{n} \begin{array}{ll}\text { Mea } \\
\end{array}$ & SD & & \\
\hline Asymptomatic acute HIV group & 160 & 9.71 & 2.58 & \multirow[t]{3}{*}{88.66} & \multirow[t]{3}{*}{.001} \\
\hline Symptomatic acute HIV group & 160 & $2^{11.6}$ & 2.17 & & \\
\hline AIDS indicator group & 160 & $4^{13.0}$ & 1.92 & & \\
\hline Total & 480 & & & & \\
\hline
\end{tabular}

Table 1 shows the mean score and standard deviation on death anxiety of asymptomatic acute HIV group, symptomatic acute HIV group and AIDS indicator group. Symptomatic acute HIV group has obtained greater mean score $(M=11.62, S D=2.17)$ on death anxiety compared to asymptomatic acute HIV group $(M=9.71, S D=2.58)$ and AIDS indicator group has obtained greater mean score $(M=13.04, S D=1.92)$ compared to symptomatic acute HIV group. In comparing significant mean differences between groups ANOVA is calculated and the obtained $F(2,477)=88.66, p<.01$.As the $\mathrm{p}$ value is lesser than the .01 indicating high level of significance. Therefore, it can be said that the AIDS indicator condition group has revealed greater level of death anxiety compared to the asymptomatic acute HIV group and symptomatic acute HIV condition group.

Table 2, Shows the multiple comparisons of three groups on death anxiety using Post hoc Tukey's HSD test

\begin{tabular}{|c|c|c|c|c|}
\hline HSD & Multiple comp & rison & & \\
\hline Phase (I) & Phase (J) & $\begin{array}{l}\text { Mean difference } \\
(I-J)\end{array}$ & $\begin{array}{l}\text { Std.err } \\
\text { or }\end{array}$ & $\mathrm{P}$ \\
\hline \multirow[t]{2}{*}{ Asymptomatic } & Symptomatic & -1.91 & \begin{tabular}{|l|l|}
.25 \\
\end{tabular} & .001 \\
\hline & AIDS & -3.33 & .25 & .001 \\
\hline \multirow[t]{2}{*}{ Symptomatic } & Asymptomatic & 1.91 & .25 & .001 \\
\hline & AIDS & -1.41 & .25 & .001 \\
\hline \multirow[t]{2}{*}{ AIDS } & Asymptomatic & 3.33 & .25 & .001 \\
\hline & Symptomatic & 1.41 & .25 & .001 \\
\hline
\end{tabular}

Post hoc analyses were conducted given the statistical significant omnibus ANOVA test, specifically Tukey's HSD test were conducted to find out on all possible pair wise contrast. 


\section{Death Anxiety among Asymptomatic Acute HIV Condition, Clinically Symptomatic Condition and Aids Indicator Condition Groups}

Group 1 (asymptomatic acute HIV condition group; $M=9.71, S D=2.58$ ), and group 2 (clinically symptomatic acute HIV condition group; $M=11.62, S D=2.17$ ) and group 1 and group 3 (AIDS indicator group; $M=13.04, S D=1.92)$. The pairs of groups were found to be significantly different $(\mathrm{p}<.01)$.

\section{HYPOTHESES TESTING}

The formulated hypothesis 1 that clinically symptomatic acute HIV Condition group exhibits higher level of death anxiety compared to asymptomatic acute HIV condition group and the results indicating statistically significant mean differences. Hypothesis 2 which stated that clinically symptomatic acute HIV condition group exhibits higher level of death anxiety compared to AIDS indicator condition group, though the mean differences are statistically significant, but the Symptomatic condition group had exhibited lower level of death anxiety compared to AIDS indicator group. Hence there is no sufficient evidence to support H2.The overall findings showed that the level of death anxiety across disease progression has been increased.

\section{DISCUSSION}

A review of the literature demonstrates frequent contradictions in the severity of emotional disturbances in subjects at different stages of HIV illness. The objective of the paper is to examining whether death anxiety varies across Asymptomatic Acute HIV condition, Clinically Symptomatic Condition and AIDS Indicator Condition group. Past research (Hintze et al., 1993) has also provided strong evidence for the existence of death anxiety in the HIV population.

The findings revealed that the level of death anxiety considerably varies across disease progression from HIV to AIDS and it clearly found that symptomatic acute HIV condition group has greater level of death anxiety compared to asymptomatic HIV acute condition group. A previous study conducted by Jadresic, Ricco, Hawkins, Wilson, and Thompson (1994); Catania, Turner, Choi, and Coates (1992) supports the present findings.

A study conducted by Kurdek and Siesky (1990) reported the contrast findings for the present findings. That study was the first study to utilize sero-negative controls, reporting that asymptomatic subjects demonstrated worse psychological functioning when compared to symptomatic and sero-negative controls. These asymptomatic subjects reported greater death anxiety, psychological distress and lower optimism despite the worse health profile exhibited by the symptomatic group. Data from symptomatic patients in this study were analysed as a whole and were not classified into AIDS of AIDS Related Complex (ARC). This study also utilized a small sample size. Both of these critiques of the methodology limit the power of these findings.

Another finding of this study in relation with the $\mathrm{H} 2$ is that AIDS indicator group has significantly greater level of death anxiety compared to asymptomatic and symptomatic acute 


\section{Death Anxiety among Asymptomatic Acute HIV Condition, Clinically Symptomatic Condition and Aids Indicator Condition Groups}

HIVcondition groups. A previous study conducted by Franks, Templer, Cappelletty, \& Kauffman (1987); Hayslip, Luhr, and Beyerlein (1991) found similar results.

Symptomatic acute HIV condition group exhibits greater level of death anxiety because, they may experience more stigmas due to observable physical symptoms of disease in their body compare to asymptomatic acute HIV condition group. In the view points of Jadresicet. al (1994)symptomatic acute HIV condition group has greater level of death anxiety as they experience symptoms of the disease; First symptoms of immune system dysfunction become evident during the early symptomatic stage of infection. This period is also referred to as AIDSrelated complex (ARC). The symptoms and conditions that develop during this period similar but are not as severe as symptoms that define the diagnosis of AIDS. AIDS indicator group exhibits greater level of death anxiety as they experience greater amount Psychopathology may be one of the reason and Templer (1976) also pointed out that Psychiatric patients and persons who demonstrate significant levels of psychopathology exhibit elevated levels of death anxiety.

\section{IMPLICATIONS}

This study provided some important implications. First, the findings are directly useful to the targeted population that, by knowing their level of death anxiety across disease progression i.e. asymptomatic HIV condition group, Symptomatic acute HIV condition group and AIDS indicator group attempts can be made to reduce the level of death anxiety and interns improve their mental health. Second, the findings may use for further research in knowing associated factors with death anxiety across disease progression. Third, these findings may be used in planning interventional programs to enhance the quality of life of the targeted population.

\section{CONCLUSION}

The death anxiety increases across disease progression from HIV to AIDS.

\section{REFERENCES}

Ammassari, A., Antinori, A., Aloisi, M. S., Trotta, M. P., Murri, R., Bartoli, L., \&Starace, F. (2004). Depressive symptoms, neurocognitive impairment, and adherence to highly active antiretroviral therapy among HIV-infected persons. Psychosomatics, 45(5), 394-402.

Atikinson, J. H., Grant, I., Kennedy, C. J., Richman, D. D., Spector, S. A., McCutchan, A. (1988). Prevalence of Psychiatric Disorders Among Men Infected with Human Immunodeficiency Virus. Archives of General Psychiatry, 45, 859-864.

Atkinson, H., Heaton,R,. and Patterson, T. (2007). Two-year prospective study of major depressive disorder in HIV+ men. Journal of Affect Disorder, 108:225-234.

Baer, J. W., Dwyer, P. C., and Lewitter-Koehler, S. (1988). Knowledge about AIDS among psychiatric inpatients. Psychiatric Services, 39(9), 986-988.

Baillargeon, J., Grady, J., Borucki, M.J. (1999).Immunological predictors of HIV-related survival. International Journal of STD/AIDS,10:467-470. 
Baillargeon, J.,Borucki, M., Black, S.A., Dunn, K. (1999).Determinants of survival in HIVpositive patients. International Journal of STD/AIDS,10:22-27.

Bartlett, J. G., and Finkbeiner, A. K. (1993). The Guide to Living with HIV Infection. Baltimore and London; The John Hopkins University Press.

Catania, J. A., Turner, H. A., Choi, K., and Coates, T. J. (1992). Coping with death anxiety: Help-seeking and social support among gay men with various HIV diagnoses. AIDS, 6, 999-1005.

Centers for Disease Control and Prevention. (1993). revised classification system for HIV infection and expanded surveillance case definition for AIDS among adolescents and adults.MMWR Recommendations and Reports.18:41(RR-17), 1-19.

Ciesla, J. A., and Roberts, J. E. (2001).Meta-analysis of the relationship between HIV infection and risk for depressive disorders. Meta, 158(5).

Foa, E. B., Steketee, G. S., and Ozarow, B. (1985). Behavior therapy with obsessivecompulsives: From theory to treatment. In M. Mavissakalian (Eds.), Obsessive compulsive disorder: Psychological and pharmacological treatment. New York: Plenum Press.

Foa, E. B.,andKozak, M. J. (1985). Treatment of anxiety disorders: Implications for psychopathology. In A. H. Tuma and J. D. Maser (Eds.), Anxiety and the anxiety disorders. Hillsdale, NJ: Erlbaum.

Franks, K., Templer, D. I., Cappelletty, G. G., and Kauffman, I. (1990). Exploration of death anxiety as a function of religious variables in gay men with and without AIDS. Omega, $22(1), 43-50$.

Gonzalez, J. S., Batchelder, A. W., Psaros, C., andSafren, S. A. (2011). Depression and HIV/AIDS treatment no adherence: a review and meta-analysis. Journal of acquired immune deficiency syndromes (1999), 58(2).

Green, J. and Hedge, B. (1991). Counselling and Stress in HIV Infection and AIDS. In C.L. Cooper and M. Watson (Ed.), Cancer and Stress: Psychological, Biological, and Coping Studies (pp. 237-255). New York: John Wiey\& Sons Ltd.

Harlow, J. L. (1976). The relationship between nurse behavior and attitudes toward terminal patients and nurse exposure to three desensitization experimental conditions. Unpublished doctoral dissertation, Florida State University, Tallahassee.

Hayslip, B., Luhr, D. D., and Beyerlein, M. M. (1991). Levels of death anxiety in terminally ill men: A pilot study. Omega, 24 (1) 13-19.

Hedge, B., andSherr, L. (1995).Psychological needs and HIV/AIDS. Clinical Psychology \& Psychotherapy, 2(4), 203-209.

Hintze, J, Templer, D. I., Cappelletty, G. G, and Frederick, W. (1993). Death depression and death anxiety in HIV-infected males. Death Studies, 17 (4), 333-341.

Jadresic, D., Riccio, M., Hawkins, D. A., Wilson, B. (1994). Long-term impact of HIV diagnosis on mood and substance use: St. Stephen's cohort study. International Journal of STD and AIDS, 5, (4), 248-252. 


\section{Death Anxiety among Asymptomatic Acute HIV Condition, Clinically Symptomatic Condition and Aids Indicator Condition Groups}

Kessler, R. C., O’Brien, K, Joseph, J. G., Ostrow, D. G. (1988). Effects of HIV infection, perceived health and clinical status on a cohort at risk for AIDS. Social Science and Medicine, 27, (6), 569-578.

King, M. B., (1989). Psychosocial status of 192 out-patients with HIV infection and AIDS. British Journal of Psychiatry, 154, 237-242.

Kurdek, L. A. andSiesky, G. (1990). the Nature and Correlates of Psychological Adjustment in Gay Men with AIDS-Related Conditions. Journal of Applied Social Psychology, 20, (10), 846-860.

Leserman, J., Petitto, J. M., Gu, H., Gaynes, B. N., Barroso, J., Golden, R. N., and Evans, D. L. (2002). Progression to AIDS, a clinical AIDS condition and mortality: psychosocial and physiological predictors. Psychological Medicine, 32(6), 1059-1073.

Lonetto, R., and Templer, D. I. (1986). Death Anxiety. Washington: Harper \& Row.

Miller, A. K., Lee, B. L., and Henderson, C. E. (2012).Death anxiety in persons with HIV/AIDS; a systematic review \&meta-analysis; Death studies, 36(7), 640-63.

Moore, R. D. and Chaisson, R. E.(1999).Natural history of HIV infection in the era of combination antiretroviral therapy.AIDS,13:1933-1942.

Passik, S. D., McDonald, M. V., Rosenfeld, B. D., and Breitbart, W. S. (1995). End of life issues in patients with AIDS: clinical and research considerations. Journal of Pharmaceutical Care in Pain \& Symptom Control, 3(3-4), 91-111.

Pérez-Hoyos, S., delAmo, J., Muga, R., del Romero, J., de Olalla, P. G., Guerrero, R., and Hernàndez-Aguado, I. (2003). Effectiveness of highly active antiretroviral therapy in Spanish cohorts of HIV seroconverters: differences by transmission category. Aids, 17(3), 353-359.

Perry, S., Jacobsberg, L. Fishman, B., Frances, A., Bobo, J., and Jacobsberg, B. K. (1990).Psychiatric diagnosis before serological testing for the human immunodeficiency virus.American Journal of Psychiatry, 147, 89-93.

Rabkin, J.G., Williams, J.B., Remien, R.H., Goetz, R., Kertzner, R., and Gorman, J.M. (1991). Depression, Distress, Lymphocyte Subsets, and Human Immunodeficiency Virus Symptoms on Two Occasions in HIV-Positive Homosexual Men. Archives of General Psychiatry, 48, 111-119.

Thomason, B. T., Bachanas, P. J., and Campos, P. E. (1997).Cognitive behavioral interventions with persons affected by HIV/AIDS. Cognitive and Behavioral Practice, 3(2), 417-442.

Tross, S., \& Hirsch, D. (1988). Psychological distress and neurological complications of HIV infection and AIDS. American Psychologist, 43, 929-934.

UNAIDS (2015). The Joint United Nations Programme on HIV/AIDS - World AIDS Day report .Fact Sheet 2015.Retrived on 07.04.2016 at http://www.unaids.org/en/resources/campaigns/HowAIDSchangedeverything/factsheet. 